\title{
PENGARUH KECENDERUNGAN CONSUMER ETHNOCENTRISM DOMESTIC PRODUCT BELIEF TERHADAP KEIGINAN UNTUK MEMBELI PRODUK ELEKTRONIK DI KOTA MATARAM, NUSA TENGGARA BARAT
}

\author{
Rusdan $^{1}$, Baiq Ismiwati ${ }^{2}$, Sulhaini $^{3}$, Rahman Dayani $^{4}$ \\ ${ }^{I}$ Fakultas Ekonomi dan Bisnis Universitas Mataram, erdanmuslim58@gmail.com \\ ${ }^{2}$ Fakultas Ekonomi dan Bisnis Universitas Mataram, baiqimiwati@unram.ac.id \\ ${ }^{3}$ Fakultas Ekonomi dan Bisnis Universitas Mataram, sulhaini@unram.ac.id \\ ${ }^{4}$ Fakultas Ekonomi dan Bisnis Universitas Mataram, rahmandayani@gmail.com
}

\begin{abstract}
ABSTRAK
Tujuan utama dari penelitian ini adalah untuk menguji pengaruh kecenderungan ethnocentrisme kepercayaan terhadap produk dalam negeri dan keiginan untuk membeli. Survei dilakukan di kalangan mahasiswa Universitas Mataram. Terdapat seratus mahasiswa sebagai sampel yang ditentukan secara accidental selama dua minggu pengumpulan data. Mayoritas diantara mereka adalah mahasiswa Fakultas Ekonomi dan Bisnis. Penelitian ini menemukan bahwa kecenderungan ethnocentrisme di kalangan mahasiswa yang merupakan konsumen muda belum sangat kuat. Hal ini juga terlihat pada domestic product belief dan keinginan untuk membeli produk elektronik buatan dalam negeri. Namun demikian, kecenderungan ini berpengaruh kuat terhadap domestic product beleif dan keinginan untuk membeli. Ini berarti ditengah era pasar bebas, sangatlah penting untuk memperkuat kecenderungan tersebut di kalangan konsumen muda terdidik demi kepentingan ekonomi bangsa.
\end{abstract}

Katakunci: consumer ethnocentrism, kepercayaan pada produk domestik, keinginan untuk membeli

\begin{abstract}
The main objective of the study was to examine the effect of consumer ethnocentrism toward domestic product belief and willingness to buy. The survey was carried out among students of the University of Mataram. A hundred of student sample were accidently determined during two weeks of data collection. Majority of them were students of the Faculty of Economic and Businesess. The study found that ethncentrism among students (young consumers) is still not really strong/medium level. This was seen also on domestic product belief and willingness to buy. Nevertheless, the tendency has a strong effect on domestic product belief and willingness to buy domestically made electronic products. This means it is important to strengthen the tendency among young (educated) consumers for the national economy.
\end{abstract}

Keyword: Consumer ethncentrism, domestic product belief, willingness to buy

\section{PENDAHULUAN}

Di era pasar bebas yang saat ini sudah dimasuki oleh berbagai negara termasuk Indonesia, konsumen memiliki lebih banyak pilihan dan semakin familiar dengan produk dari berbagai negara lain. Hal ini didukung oleh kemajuan tekhnologi informasi memungkinkaan penduduk Indonesia semakin familiar dengan produk/merek global. Mereka juga memiliki peluang yang semakin besar untuk membandingkan produk lokal dan asing ketika shopping baik offline maupun online. Mereka dengan mudah 
mengevaluasi dan menilai berbagai hal atau fitur produk dalam memlih produk di antara berbagai pilihan yang ada. Merek, kemasan, harga citra produk, kategori produk, kualitas bahkan country of origin (COO) atau citra negara asal produk dapat menjadi faktor yang menentukan persepsi dan sikap konsumen dalam menentukan pilihan (Karami et al, 2011). Beberapa negara memiliki citra positif yang dapat memberikan keunggulan bagi produk yang berasal dari negara-negara tersebut.

Literatur terkait country of origin effect menjelaskan bahwa konsumen cenderung memiliki sikap dan preferensi terhadap produk tertentu yang dibuat di negera tertentu bergantung pada persepsi mereka terhadap negara asal. Seringkali di negara berkembang para konsumen memiliki preferensi yang kuat terhadap produk dari negaranegara maju (Biswas et al., 2011). Para konsumen tersebut menganggap produk dari negara maju memiliki kualitas yang lebih bagus dibanding yang berasal dari negerinya sendiri, mereka mendambakan produk impor dari negara maju (Barbu, 2011). Minat membeli suatu produk berkaitan dengan karakteristik ekonomi, politik, technologi dan sosial dari suatu negara (Wang and Yang, 2008). Sebagian dari negara-negara di Asia seperti Taiwan, Korea dan Singapore yang telah berhasil mencapai taraf hidup yang hampir sama dengan negara-negara maju di Eropa, tetap saja dipersepsikan oleh konsumen Eropa kurang mampu membuat produk berkualitas (Speece dan Nguyen, 2005). Hal ini disebabkan adanya persepsi terhadap kemampuan negara-negara Asia (terkecuali Jepang) dalam memproduksi suatu produk dijadikan dasar dalam mengevaluasi produk. Di awal proses industrialisasinya, perusahaan Jepang melakukannya secara perlahan, tidak agresif untuk menguasai pasar dunia dalam waktu singkat. Pada saat itu kualitas produk Jepang sangat rendah dan dijual dengan harga murah sehingga terkesan produk murahan dan konsumen duni belum memiliki kepercayaan yang tinggi terhadap produk-produk elektronik dari negera tersebut. Namun, secara bertahap pula bangsa Jepang melakukan perubahan dari memasarkan produk berkualitas rendah menjadi memasarkan produk berkualitas tinggi yang dijual dengan harga tinggi. Jepang tak lagi memiliki citra COO yang rendah tapi tinggi dan sangat baik. Bahkan khusus untuk kategori produk elektronik rumah tangga tidak ada negara lain yang memiliki citra sebaik Jepang. Di Inggris, terdapat dua merek bernuansa Jepang yaitu: Hinari dan Matsui yang sesungguhnya dimiliki dan dikembangkan oleh perusahaan elektronik setempat. Hal ini untuk mempengaruhi pemikiran konsumen supaya beranggapan bahwa merek-merek tersebut berasal dari Jepang, padahal sesungguhnya merek asli dari Inggris.

Reputasi bangsa Jpeang sebagai sumber produk elekronik yang positif mampu diciptakan dengan kesungguhan untuk meningkatkan kualitas secara berkelanjutan. Ketimbang menjual dengan harga murah, mereka menawarkan "tambahan" pada harga penuh (Speece dan Nguyen, 2005). Ini menunjukkan bahwa perusahaan Jepang berupaya meningkatkan daya saingnya dengan meningkatkan kualias dan tentunya nilai pelanggan. Hal ini sangat dimungkinkan karena adanya dukungan yang kuat dari konsumen dalam negerinya yang terkenal memiliki kecenderung ethnocentrism yang sangat kuat. Kecenderungan ini pula yang menjadi rintangan bagi produk impor untuk menguasai pasar Jepang. produk dalam negeri menjadi tuan di pasar domestik. Kecenderungan ini merupakan benteng pelindung bagi industri dan ekonomi nasional di era pasar bebas yang tidak lagi mengenal proteksi dalam bentuk tarif, quota dan lain.lain. Sehingga kecenderungan ini sangat penting terutama di negara-negara berkembang (Banfo, 2012).

Sejak tahun 2010, Indonesia dan negara-negara anggota ASEAN lainnya 
memasuki era free trade zone dengan Cina tahun 2010. Konsekuensi dari kesepakatan free trade zone ini membuat produk lokal harus bersaing ketat dengan produk impor dari negara-negara tersebut. Produk impor terutama dari Cina semakin membanjiri pasar dalam negeri. Produk buatan Cina lebih diminati dan dianggap memiliki kualitas yang lebih baik oleh konsumen Indonesia (Sulhaini dan Mulyono, 2015). Oleh karena itu perlu upaya untuk meningkatkan kesadaran konsumen dalam negeri khususnya di generasi muda terdidik sepertimahasiswa untuk membeli atau menggunakan produk dalam negeri. Penggunaan produk dalam negeri tentunya harus dilandasi oleh kepercayaan terhadap produk yang kuat (domestic product belief). Hal ini perlu untuk mendukung industri dalam negeri yang kuat dan mampu menyerap tenaga kerja lokal sehingga dapat menguatkan kondisi ekonomi bangsa Indonesia. Penelitian ini ditujukan untuk menguji pengaruh consumer ethnocentrism terhadap domestic product belief dan minat membeli produk dalam negeri di kalangan mahasiswa di kota Mataram Nusa Tenggara Barat. Penelitian ini memiliki arti penting karena bangsa ini telah enam tahun memasuki era pasar bebas dan memerlukan konsumen domestik yang berpihak kepada produk domestik. Literatur country of origin effect secara umum menjelaskan bahwa konsumen di kota-kota besar cenderung lebih terbuka terhadap produk impor dan evaluasi lebih didasari oleh penilaian rasional bila dibandingkan dengan konsumen di kota-kota kecil. Hal ini menunjukkan bahwa konsumen di kota kecil lebih ethnocentris dibanding mereka yang berada di kota besar. Namun demikian, sebagaimana telah disebutkan sebelumnya bahwa konsumen di negara berkembang cenderung memiliki preferensi, persepsi dan sikap yang lebih kuat/positif terhadap produk impor dibanding produk lokal. Konsumen di negara berkembang menunjukkan kecenderungan ethnocentrism yang rendah (Abedniya and Zaem, 2011). Hal ini menunjukkan pentingnya untuk mengukur dan menguji kecenderungan ethnocentrisme dan dampaknya terhadap keyakinan dan keinginan membeli produk dalam negeri. Oleh karena itu, diharapkan bahwa penelitian ini dapat berkontribusi pada literature country of origin effect dengan memberi bukti empiris dari sebuah kota yang relatif kecil/madya di sebuah negara berkembang yaitu Indonesia.

\section{Perumusan Masalah}

1. Bagaimanakah pengaruh consumer ethnocentrism terhadap domestic product belief ?

2. Bagaimanakah pengaruh domestic product belief terhadap keputusan pembelian produk dalam negeri?

3. Bagaimanakah pengaruh consumer ethnocentrism terhadap keputusan pembelian produk buatan dalam negeri?

4. Bagaimanakah pengaruh Consumer ethnocentism secara tidak langsung terhadap keputusan pembelian melalui product belief pada produk dalam negeri?

\section{Kerangka Teoritis dan Hipotesa}

Persepsi terhadap suatu produk dapat dipengaruhi oleh citra negara asal sebagai telah diulas pada bagian pendahuluan. Konsumen di sebuah negara memandang kualitas produk impor cukup baik tetapi tetap memandang produk dalam negeri lebih baik karena ikatan emosional terhadap negerinya sendiri (Chinen \& Sun, 2011; Abedniya \& Zaem, 2011). Ini menggambarkan persepsi terhadap produk dalam negeri tergantung pada kecenderungan ethnocentrisme di kalangan konsumen dalam negeri. Kajian berikut ditujukan untuk mendalami konsep consumer ethnocentrism dan pengaruhnya 
terhadap perilaku konsumen. Ini akan menjadi dasar untuk merumuskan hipotesa penelitian.

Konsep consumer ethnocentrism (CE) secara konsisten mendapatkan perhatian besar diantara para peneliti di bidang pemasaran internasional di berbagai belahan dunia. Konsep ini berasal dari teori sosiologi yang menggambarkan keyakinan individu bahwa grupnya yang terbaik/superior dan menjadi pusat dunia (Shimp \& Sharma, 1987).CE memacu keyakinan bahwa etnis atau kelompok budayanya sebagai yang terpenting sedangan grup yang lain dinilai dalam kaitannya dengan grupnya (Auruskeviciene et al., 2012). Konsep ini dipadukan ke dalam literatur manajemen pemasaran dan memunculkan konsep consumer ethnocentrism (CE). Konsep ini mengacu pada kecenderungan untuk membedakan produk asing dan lokal dan penolakan akan produk asing karena adanya adanya nasiolisme yang kuat (Shankarmahesh, 2006). Oleh karena itu, CE menggambarkan pembedaan grup konsumen yang memiliki preferens yang kuat terhadap produk lokal/domestik atas produk asing (Huddleston et al., 2001). Study dariShimp and Sharma (1987)telah memberikan pemahaman yang mendasar terkait konsep ini. Mereka menjelaskan bahwa CE meberikan konsumen a sense of identity, feeling of belonging and acceptable or unacceptable purchase behaviour sehingga CE menunjukkan pula keyakinan konsumen dan kepantasan moral untuk mengkosumsi produk impor.

Konsep ini berbeda dengan country of origin/country image. Country image menggambarkan aspek cognitivedan affective dalam proses pengambila keputusan konsumen, sementarae CE menunjukkan aspek affective dan normative dalam perilaku konsumen. Aspek normatif membuat konsep CE menjadi konsep yang unik (Shankarmahesh, 2006). Country image berkaitan denganatribut produk sedangkan CE menuunjukkan standar norma sosial dan moral yang dapat diterima dan menjadi standar kepantasan dalam perilaku konsumen Konsumen dengan kecedenderungan ethnocentrism yang kuat akan mengevaluasi produk berdasarkan kepantasan dar sisi moral untuk membeli produk impor (Huddleston et al., 2001).

$\boldsymbol{C E}$ didefinisikan pula sebagai penolakan untuk membeli produk impor karena adanya keyanikan hal itu akan merusak ekonomi dan kesejahteraan dalam negeri (Rybinaetal., 2010;Banfo, 2012). Ethnocentrisme merupakan ide serta keyakinan bahwa produk dari negaranya superior dibanding dari negara lain (Banfo, 2012). Ethnocentrisme merupakan kecenderungan pada konsumen ditunjukkan oleh preferensi yang kuat terhadap produk dalam negeri karena adanya kewajiban moral terhadap perekonomian negaranya sendiri. Kecenderungan ethnocentris menunjukkan dimensi emotional yang berkaitan dengan pembelian produk asing serta implikasi bahwa pilihan dapat mengancam industri dalam negeri bahkan keamanan nasional. Dengan demikian konsumen yang ethnocentris akan menilai produk secara lebih subyektif dibanding konsumen yang tidak memiliki kecenderungan ethnocentris. Konsumen yang ethnosentris percaya bahwa membeli produk asing secara moral adalah salah (Banfo, 2012; Al Ganideh and Al Taee, 2012).

Selanjutnya, CE dipandang pula sebagai keseluruhan sikap terhadap produk ataupun merek impor vs domestik berkaitan dengan reaksi affektif, cognitive bias and pilihan (Sharma, 2015). Ini menggambarkan sisi emosional dan perilaku dari CE yang menekankan pada kecedenerungan pengutamaan produk dalam negeri dan penolakan produk impor. Ini merupakan penekanan pada aspek normatif di mana konsumen akan memiliki perasaan untuk harus memilih produk dalam negeri ketimbang produk impor (Shankarmahesh, 2006). CE cenderung menguat di saat konsumen dalam negeri 
melihat/merasa adanya ancaman terhadap kesejahteraan ekonomi bagsanya (Lanz dan Loeb, 1996).

Konsumen yang memiliki CE yang kuat akan menekankan pada aspek positif dari negeranya sendiri sedangkan konsumen dengan $\mathrm{CE}$ yang rendah akan mengunakan penilaian objective terhadap atribut produk dan tidak menunjukkan penialian yang bias terhadap produk impor (Jain and Jain, 2013). Sehingga CE yang lemah membuat seorang konsumen lebih realistis dan objective dalam menilai produk dari negara lain. Mereka akan mengevaluasi produk dengan melihat atribut produk seperti desain, harga, kualitas dan nilai serta menempatkan informasi terkait negara asal sebagai informasi yang tidak terlalu penting. Sebaliknya, konsumen dengan CE yang kuat akan memiliki ikatan emosional yang kuat dengan negaranya sendiri dan menunjukkan loyalitas tinggi terhadap produk dari negaranya sendiri. Mereka selalu mencari informasi asal produk untuk memastikan bahwa mereka tidak salah membeli produk.

Konsumen yang memiliki kecenderungan ethnocentrism yang kuat menngunakan pertimbangan rasional, tidak memperdulikan perbdeaan kualitas dan mengorbankan self-interest demi ekonomi negaranya (Orth \&Firbasova, 2003). Meskipun produk asing/impor dianggap lebih berkualitas, mereka tidak memiliki keinginan untuk membelinya karena mereka menganggap produk buatan dalam negeri lebih tepat (Oyeniyi, 2009;Chinen\&Sun, 2011). Bahkan mereka dapat pula menganggap produk dalam negeri jauh lebih baik/superior dibanding produk sejenis dari negara lain (Abedniya\&Zaem, 2011), hal ini menyebakan mereka memiliki persepsi terhadap produk yang lebih positif, mereka memiliki keyakinan terhadap produk buatan negaranya sendiri lebih baik dan cenderung overestimate kualitasnya(Watson \& Wright, 2000;Abedniya\&Zaem, 2011). Dengan demikian, dapat dikatakan bahwa konsumen yang ethnosentris akan memiliki keyakinan terhadap produk dalam negeri yang kuat. Hal ini disebabkan oleh keinginan mereka untuk menunjukkan cinta dan kesetiaanya pada negaranya sendiri. Evaluasi mereka terhadap produk dalam negeri dipengaruhi oleh perasaann cintanya dan bukan berdasakan pada pertimbangani rasionalnya (Balabanisetal., 2001). Sebaliknya konsumen dengan ethnosentrisme yang lemah akan mengevaluasi produk yang ada di pasar dengan melihat kualitas aktual dan mungkin saja menganggap produk impor lebih baik (Abedniya\&Zaem, 2011). Mereka mengevaluasi fitur produk dan justru mengganggap lebih baik hanya karena berasal dari luar negeri (Al Ganideh\& Al Taee, 2012).Secara singkat dapat dikatakan bahwa CE membuat konsumen berperilaku positif terhadap produk dalam negeri, begitu pula sebaliknya.

Penelitian-penenlitian terdahulu di negara-negara maju menunjukkan bahwa hasil yang seragam di mana konsumennya menganggap produk domestik lebih baik dan menganggap produk impor sebagai produk yang buruk. Mereka memiliki sikap positif dan preferns yang kuat terhadap produk buatan negerinya sendiri dan merasa memiliki kewajiban moral untuk membeli produk domestik. It was also found a negative relationship between $\mathrm{CE}$ and foreign product evaluation meaning that high ethnocentric consumers negatively evaluate imported products (Bawa, 2004). Hasil penelitian Sulhaini (2016) menegaskan bahwa keyakinan terhadap produk dalam negeri mendorong konsumen untuk membeli produk dalam negeri. Hal ini menyiratkan bahwa produsen dalam negeri harus berupaya meningkatkan product belief untuk meningkatkan minat beli. Mereka perlu investasi pada peningkatkan kemampuan inovasi pada desain, kualitas relibilitas dan kemajuan teknologi. Dengan demikian dapat dirumuskan hipotesa sebagai berikut: 


\section{H1: Semakin kuat consumer ethnocentrism semakin kuat pula domestic product belief}

H2: Semakin kuat domestic product belief semakin kuat willingenness to buy produk dalam negeri

Konsumen ethnosentris akan memiliki keyakinan yang berkaitan dengan kepantasan bahkan moralitas dalam membeli produk asing. Etnosentrisme memberikan konsumen perasaan memiliki, identitas dan sebuah pemahaman atas perilaku membeli yang dapat diterima atau tidak didalam group atau masyarakatnya (Rybina et al., 2010). Konsumen yang ethnocentric tidak memiliki minat untuk membeli dan menggunakan produk asing karena mereka berpikir dapat merusak ekonomi dalam negeri. Konsumen menganggap pilihan mereka akan produk dalam negeri akan memiliki kekuatan besar terhadap kesejahteraan negerinya sendiri. Mereka menunjukkan bahwa produk dalam negeri yang terpavorit dan sekaligus menunjukkan rasa cinta dan kesetiaannya kepada bangsanya sendiri. Mengkonsumsi produk asing akan merugikan produsen dalam negeri, meningkatkan pengangguran dan memperburuk kondisi ekonomi di dalam negeri. Para konsumen yang memiliki pandangan seperti ini dapat menunjukkan persepsi yang mungkin berlebihan terhadap kualitas dan nilai dari produk dalam negeri serta memiliki preferensi yang tinggi pula terhadap produk dalam negeri sehingga sikap ethnosentrisme memiliki pengaruh negatif terhadap produk asing (Rybina et al., 2010). Minat beli konsumen terhadap produk dalam negeri atau asing tergantung berbagai faktor seperti ethnocentrisme dan penilaian obyektif atas produks.

Konsumen yang sangat ethnocentris memandang bahwa membeli produk dalam negeri sebagai kewajiban bagi setiap warga negara untuk menunjukkan kesetiaan dan komitmen terhadap kesejahteraan bangsanya (Rybinaetal., 2010). Kecederungan ini merupakan keyakinan yang dimiliki oleh konsumen terkait kepantasan dan moralitas dalam memilih produk dalam negeri dibandingkan produk impor (Shimp and Sharma, 1987).

Penelitian terdahulu di berbagai negara berkembang menunjukkan hasil yang beragam. Shah and Ibrahim (2012) menunjukkan butki bahwa muslim Malaysia cenderung memiliki ethnocentrisme yang kuat dan secara negatif menilai produkproduk impor dari Amerika serikat. Sementara itu hasil penelitian di Malaysia yang dilakukan olehAbedniya and Zaem (2011) justru menunjukkan bahwa konsumen di negara itu kurang ethnosentris dan kurang menyukai produk dalam negeri. Ini merupakan pertanda melemahnya patriotisme dikalangan konsumen dalam negeri (Mohamed et al., 2011).

Konsep CE menjelaskan bahwa secara moral, membeli produk impor adalah salah dan tidak dapat diterima karena tidak menunjukkan patriotisme dan merusak industri dalam negeri, lapangan kerja dan ekonomi secara keseluruhan. Konsumen dengan kecenderungan ethnocentrisme yang kuat tidak akan membeli produk asing karena pertimbangan implikasi sosial dan ekonomi (Notarietal., 2011) dan mereka memiliki keyakinan bahwa dari sisi moral dan etika, membeli produk asing adalah salah (Abedniya and Zaem, 2011; Al Ganideh and Al Taee, 2012). Ini akan mendorong mereka untuk mengkonsumsi produk buatan dalam negeri (Rybinaetal., 2010). Secara singkat, willingness to buy produk domestik bergantung pada CE (Powersetal., 2008; Rybinaetal., 2010; Brkicetal., 2011). Sehingga, hipotesa berikut dapat diusulkan: 
H3: semakin kuat consumer ethnocentrism semakin kuat willingness to buy produk buatan dalam negeri

H4. Consumer ethnocentism secara tidak langsung berpengaruh terhadap willingness to buy melalui product belief produk dalam negeri

Secara singkat diskusi dan hipotesa yang teridentifikasi dapat digambarkan sebagaimana kerangka konseptual di bawah ini

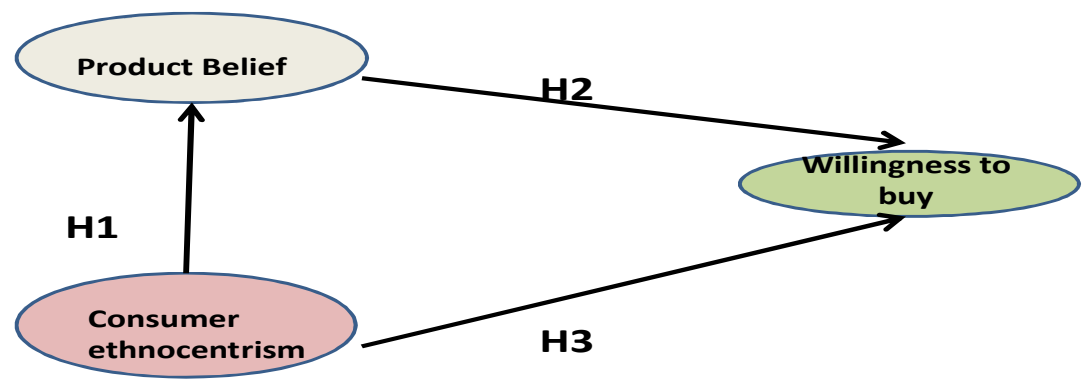

\section{Gambar 1. Kerangka Konseptual}

\section{METODE PENELITIAN}

Penelitian ini merupakan penelitian asosiatif dimana consumer ethnocentrism diposisikan sebagai variabel independen atau yang mempengaruhi variabel lainnya yaitu: domestic product belief dan willingness to buy.Populasi dari penelitian ini adalah mahasiswa di Mataram dan penentuan lokasi pengambilan data didasari pada pertimbangan heterogenitas sehingga dipilih mahasiswa di Universitas Mataram yang tersebar di berbagai fakultas. Di banding universitas lain, Universitas Mataram merupakan satu-satunya universitas negeri dan terbesar di provinsi Nusa Tenggara Barat, memiliki mahasiswa dari berbagai daerah di nusantara dengan latar belakang yang sangat beragam.Responden dari penelitian ini mayoritas berjenis kelamin perempuan (65\%) sementara laki-laki hanya 35\%. Semua responden berusia di bawah 25 tahun dan mayoritas dari mereka kuliah di fakultas Ekonomi Dan Bisnis (53\%), disusul oleh mahasiswa dari fakultas Pertanian dan $30 \%$ lain berasal dari lima fakultas yang berbeda.

Kritik terhadap penggunaan sampel mahasiswa pernah dikemukakan oleh Baker and Ballington (2002) dan Dinnie (2004). Namun demikian, dengan mempertiimbangkan pendapat Phau (2010), bahwa mereka tepat dan representatif dalam penelitian perilaku konsumen. Mereka adalah kelompok konsumen memiliki pendidikan tinggi yang dimasa yang akan datang akan menentukan perilaku konsumen domestik dan menjadi pengambil keputusan bagi kesejahteraan bangsanya. Kelompok konsumen mahasiswa ini dipilih supaya penelitian dapat mengumpulkan data dan memahami 
persepsi konsumen muda terpelajar terkait produk buatan dalam negeri. Penelitian ini menjadi semakin penting untuk dilakukan karena hasilnya akan memberikan pemahaman penting tersebut karena Indonesia sudah menjadi pasar yang semakin terbuka dan membutuhkan dukungan dari konsumen dalam negeri untuk mampu bersaing dengan produk impor.Accidental sampling akan digunakan dalam pengumpulan data selama dua minggu dengan target jumlah sampel sebanyak 100 orang. Penentuan jumlah ini didasarkan pada rekomendasi dari Hair et al (2006) untuk penelitian multivariat.

Penelitian ini fokus pada kategori produk elektronik yakni televisi karena produk yang sangat dikenal oleh konsumen (high product familiarity). Selain itu, produk televisi buatan Indonesia di pasar global dinyatakan memiliki reputasi yang kurang baik (Yim et al., 2007; Oyeniyi, 2009) sehingga penelitian ini juga akan dapat mengungkap bagaimana persepsi konsumen dalam negeri.Dalam penelitian ini, CE dioperasionalkan sebagai kecenderungan konsumen untuk menunjukkan perilaku positif terhadap produk buatan dalam negeri demi kemajuan dan kesejahteraan ekonomi bangsa Indonesia.DomesticProduct beliefdioperasionalkan dengan kepercayaan konsumen dalm negeri dengan menggunakan indikator :value for money, kualitas, reliability dan technological advancement dari produk buatan dalam negeri. Pengukuran konstruk ini dengan mengadopsi penelitian dari Bawa (2004), sementara willingness to buy diukur dengan mengadaptasi (Oberecker dan Diamantopoulos, 2011) yaitu: willingness to buy domestic electronic products, the next time of purchase, dan willingness to try the products. Khusus untuk consumer ethnocentrism, peneliian ini mengacu pada enam indikator yang digunakan oleh Rybina et al. (2010). Skala sevenpoint Likert-type $(1=$ strongly disagree to $7=$ strongly agree $)$ digunakan untuk mengukur consumer ethnocentrism dan product belief sedangkan willingness to buy menggunakan skalaseven-point semantic. Adapun hasil uji instrumen dapat dilihat pada tabel 1. Dari tabel tersebut dapat diketahui bahwa semua item memeili factor loading di atas 0.5 dan semua variabel memiliki compsite relability dan alpha cronbach di atas 0.70 lampui batas minimal dan Average Variance Extracted (AVE) di atas 0.5. Ini menjukkan validita convergent dan reliabilitas item yang baik. Sedangkan untuk uji discriminant validity dilakukan dengan membandingkan antara suare root dari AVE dengan koefisien korelasi antar variabel. Hasilnya dapat dilihat pada Tabel 2.

Selanjutnya Tabel 2. menunjukkan bahwa nilai akar kuadrat AVE (angka bertanda “*”) yang berada pada posisi diagonal dan diketik miring) setiap variabel, yang lebih besar daripada nilai korelasi dengan variabel lainnya (angka yang posisinya dalam satu baris dan satu kolom dengan AVE variabel yang bersesuaian). Dengan demikian dapat disimpulkan bahwa instrumen telah memenuhi uji validitas diskrimina yang berarti responden menganggap bahwa setiap variabel berbeda.

Tabel. 1. Hasil Uji Instrumen

\begin{tabular}{|c|l|c|c|c|c|}
\hline \multirow{2}{*}{ No. } & \multicolumn{1}{|c|}{ Item } & Standardised & AVE & $\begin{array}{c}\text { Composite } \\
\text { Reliability }\end{array}$ & $\begin{array}{c}\text { Cronbachs } \\
\text { Alpha }\end{array}$ \\
\cline { 5 - 6 } & \multicolumn{1}{|c|}{ Consumer Ethnocentrism } & & $\mathbf{0 , 6 4 0 5 0 1}$ & $\mathbf{0 , 9 1 2 1 1 9}$ & $\mathbf{0 , 8 8 6 1 1 7}$ \\
\hline 1 & $\begin{array}{l}\text { Saya selalu memilih produk } \\
\text { buatan Indonesia }\end{array}$ & 0,921882 & & & \\
\hline 2 & $\begin{array}{l}\text { Orang Indonesia yang baik harus } \\
\text { selalu membeli produk buatan } \\
\text { Indonesia }\end{array}$ & 0,801716 & & & \\
\hline
\end{tabular}




\begin{tabular}{|c|c|c|c|c|c|}
\hline \multirow{2}{*}{ No. } & Item & \multirow{2}{*}{$\begin{array}{l}\text { Standardised } \\
\text { Loading }\end{array}$} & \multirow{2}{*}{$\frac{\text { AVE }}{0,640501}$} & \multirow{2}{*}{$\begin{array}{c}\text { Composite } \\
\text { Reliability } \\
\mathbf{0 , 9 1 2 1 1 9}\end{array}$} & \multirow{2}{*}{$\begin{array}{c}\begin{array}{c}\text { Cronbachs } \\
\text { Alpha }\end{array} \\
\mathbf{0 , 8 8 6 1 1 7}\end{array}$} \\
\hline & Consumer Ethnocentrism & & & & \\
\hline 3 & $\begin{array}{l}\text { Membeli produk asing akan } \\
\text { merusak perekonomian bangsa }\end{array}$ & 0,535580 & & & \\
\hline 4 & $\begin{array}{l}\text { Saya selalu memilih produk } \\
\text { buatan Indonesia }\end{array}$ & 0,852893 & & & \\
\hline 5 & $\begin{array}{l}\text { Membeli produk asing dapat } \\
\text { menyebabkan pengangguran di } \\
\text { Indonesia }\end{array}$ & 0,698454 & & & \\
\hline 6 & $\begin{array}{l}\text { Tidak semua produk perlu } \\
\text { diimpor. Hanya produk yang } \\
\text { tidak mampu diproduksi oleh } \\
\text { Indonesia yang boleh diimpor }\end{array}$ & 0,921022 & & & \\
\hline & Domestic Product Belief & & $\mathbf{0 , 7 3 6 0 9 7}$ & 0,917488 & 0,879246 \\
\hline 1 & $\begin{array}{l}\text { Kualitas produk elektronik } \\
\text { buatan Indonesia sebanding } \\
\text { dengan harga }\end{array}$ & 0,782376 & & & \\
\hline 2 & $\begin{array}{l}\text { Produk elektronik buatan } \\
\text { Indonesia memiliki teknologi } \\
\text { maju }\end{array}$ & 0,846993 & & & \\
\hline 3 & $\begin{array}{l}\text { Produk elektronik buatan } \\
\text { Indonesia berkualitas tinggi }\end{array}$ & 0,918794 & & & \\
\hline 4 & $\begin{array}{l}\text { Produk elektronik buatan } \\
\text { Indonesia handal }\end{array}$ & 0,877892 & & & \\
\hline & Willingness to buy & & $\mathbf{0 , 7 1 7 1 7 7}$ & $\mathbf{0 , 8 8 3 3 6 8}$ & 0,801241 \\
\hline & $\begin{array}{l}\text { Saya ingin membeli produk } \\
\text { elektronik buatan Indonesia }\end{array}$ & 0,886019 & & & \\
\hline & $\begin{array}{l}\text { Saya akan membeli produk } \\
\text { elektronik buatan Indonesia bila } \\
\text { nanti saya membutuhkan produk } \\
\text { elektronik }\end{array}$ & 0,883278 & & & \\
\hline & $\begin{array}{l}\text { Saya ingin mencoba produk } \\
\text { elektronik buatan Indonesia }\end{array}$ & 0,765715 & & & \\
\hline
\end{tabular}

Tabel 2. Discriminant validity

\begin{tabular}{|l|c|c|c|}
\hline \multicolumn{1}{|c|}{ Variabel } & $\begin{array}{c}\text { Consumer } \\
\text { Ethnocentrism }\end{array}$ & $\begin{array}{c}\text { Product } \\
\text { Belief }\end{array}$ & $\begin{array}{c}\text { Willingness to } \\
\text { Buy }\end{array}$ \\
\hline $\begin{array}{l}\text { Consumer } \\
\text { Ethnocentrism }\end{array}$ & $0,800313^{*}$ & & \\
\hline Product Belief & 0,521316 & $0,857961^{*}$ & \\
\hline Willingness to Buy & 0,600742 & 0,808834 & $0,846863^{*}$ \\
\hline
\end{tabular}

(*)nilai akar kuadrat AVE

Untuk menguji goodness of fit model, kami mengikuti rekomendasi dari Widarjono (2010) yang mengatakan bahwa pengujian ini bisa dilakukan dengan melakukan ujit chi-square. Nilai Chi square dari penelitian ini adalah 1.316 sehingga dapt dikatakan dapat diterima. Widarjono (2010) menyatakan bahwa uji ini memiliki kelemahan karena sensitif terhadap jumlah sampel sehingga dapat menggunakan alternatif lain seperti 
RMSEA atau root mean squares error approximation. Dalam penelitian ini nilainya adalam 0.056 sehingga dapat dikatakan bahwa model sudah tepat..

\section{HASIL DAN PEMBAHASAN}

Tabel 3 merangkum nilai rata-rata dan kategori dari setiap item pertanyaan dari setiap variabel penelitian. Dari tabel tersebut dapat diketahui bahwa umumnya responden memiliki tanggaan dengan kategori cukup baik dan baik (rata-rata 4,87)yang memberikan makna bahwa tingkatConsumer Ethnocentrism pada kalangan mahasiswa di Mataram belum dapat dikatakan sangat kuat (kuat-medium)karena berada sedikit di atas nilai interval (pertengahan yaitu: 3,6-4,35). Ini menggambarkan kecenderungan dan dukungan yang belum sangat kuat terhadap produk dalam negeri. Kecenderungan yang sangat kuat sangat penting bagi perkembangan industri, lapangan kerja dan ekonomi makro dan daya saing produk Indonesia di tengah persaingan global ataupun regional dengan terbentuknya free trade zone ASEAN-China. Berdasarkan Tabel 3, dapat diketahui pula bahwa umumnya responden memiliki tanggaan dengan kategori percaya dan cukup percaya. Sementara rata-rata tingkat kepercayaan terhadap produk elektronik buatan dalam negeri adalah sebesar 4,26dengan kategori cukup percaya (berada pada internal nilai tengah). Hal ini bermakna bahwamahasiswa memilikitingkat kepercayaan yang belum kuat terhadap produk elektronik dalam negeri. Tabel tersebut $d$ atas juga menggambarkan bahwaumumnya responden memiliki keinginan untuk membeli produk elektronik buatan dalam negeri, Namun belum bisa dikategorikan sebagai keinginan yang sangat kuat.

Tabel 3. Frekwensi dan ketegori

\begin{tabular}{|c|c|c|c|c|c|c|c|c|c|c|}
\hline \multirow{2}{*}{$\begin{array}{l}\text { Item Consumer } \\
\text { Ethnocentrism }\end{array}$} & \multicolumn{7}{|c|}{ Frekuensi Skor Jawaban } & \multirow{2}{*}{ Total } & \multirow{2}{*}{$\begin{array}{c}\text { Rata- } \\
\text { rata }\end{array}$} & \multirow{2}{*}{ Kategori } \\
\hline & 1 & 2 & 3 & 4 & 5 & 6 & 7 & & & \\
\hline $\begin{array}{l}\text { Saya selalu memilih } \\
\text { produk buatan Indonesia }\end{array}$ & 3 & - & 10 & 44 & 11 & 14 & 18 & 474 & 4,74 & $\begin{array}{c}\text { Kuat- } \\
\text { medium }\end{array}$ \\
\hline $\begin{array}{l}\text { Orang Indonesia yang } \\
\text { baik harus selalu membeli } \\
\text { produk buatan Indonesia }\end{array}$ & 1 & 3 & 11 & 29 & 13 & 24 & 19 & 498 & 4,98 & $\begin{array}{c}\text { Kuat- } \\
\text { medium }\end{array}$ \\
\hline $\begin{array}{l}\text { Membeli produk asing } \\
\text { akan merusak } \\
\text { perekonomian bangsa }\end{array}$ & 1 & 4 & 10 & 20 & 22 & 24 & 19 & 506 & 5,06 & $\begin{array}{l}\text { Kuat- } \\
\text { medium }\end{array}$ \\
\hline $\begin{array}{l}\text { Saya selalu memilih } \\
\text { produk buatan Indonesia }\end{array}$ & 1 & 2 & 8 & 43 & 12 & 21 & 13 & 478 & 4,78 & Kuat \\
\hline $\begin{array}{l}\text { Membeli produk asing } \\
\text { dapat menyebabkan } \\
\text { pengangguran di } \\
\text { Indonesia }\end{array}$ & - & 6 & 8 & 28 & 25 & 16 & 17 & 488 & 4,88 & $\begin{array}{c}\text { Kuat- } \\
\text { medium }\end{array}$ \\
\hline $\begin{array}{l}\text { Tidak semua produk perlu } \\
\text { diimpor. Hanya produk } \\
\text { yang tidak mampu } \\
\text { diproduksi oleh Indonesia } \\
\text { yang boleh diimpor }\end{array}$ & 3 & - & 10 & 43 & 10 & 16 & 18 & 477 & 4,77 & $\begin{array}{c}\text { Kuat- } \\
\text { medium }\end{array}$ \\
\hline \multicolumn{8}{|c|}{ Rata-Rata Consumer Ethnocentrism } & 487 & 4,87 & Kuat- \\
\hline
\end{tabular}




\begin{tabular}{|c|c|c|c|c|c|c|c|c|c|c|}
\hline \multirow{2}{*}{$\begin{array}{l}\text { Item Consumer } \\
\text { Ethnocentrism }\end{array}$} & \multicolumn{7}{|c|}{ Frekuensi Skor Jawaban } & \multirow{2}{*}{ Total } & \multirow{2}{*}{$\begin{array}{c}\text { Rata- } \\
\text { rata }\end{array}$} & \multirow{2}{*}{ Kategori } \\
\hline & 1 & 2 & 3 & 4 & 5 & 6 & 7 & & & \\
\hline \multirow{3}{*}{$\begin{array}{c}\text { Item Domestic Product } \\
\text { Belief }\end{array}$} & & & & & & & & & & medium \\
\hline & \multicolumn{7}{|c|}{ Frekuensi Skor Jawaban } & \multirow{2}{*}{ Total } & \multirow{2}{*}{$\begin{array}{c}\text { Rata- } \\
\text { rata }\end{array}$} & \multirow{2}{*}{ Kategori } \\
\hline & 1 & 2 & 3 & 4 & 5 & 6 & 7 & & & \\
\hline $\begin{array}{l}\text { Kualitas produk } \\
\text { elektronik buatan } \\
\text { Indonesia sebanding } \\
\text { dengan harga }\end{array}$ & 5 & 8 & 11 & 33 & 15 & 16 & $\begin{array}{l}1 \\
2\end{array}$ & 441 & 4,41 & percaya \\
\hline $\begin{array}{l}\text { Produk elektronik } \\
\text { buatan Indonesia } \\
\text { memiliki teknologi } \\
\text { maju }\end{array}$ & 2 & 8 & 14 & 35 & 16 & 19 & 6 & 436 & 4,36 & percaya \\
\hline $\begin{array}{l}\text { Produk elektronik } \\
\text { buatan Indonesia } \\
\text { berkualitas tinggi }\end{array}$ & 2 & 11 & 15 & 40 & 16 & 7 & 9 & 414 & 4,14 & $\begin{array}{l}\text { Cukupper } \\
\text { caya }\end{array}$ \\
\hline $\begin{array}{l}\text { Produk elektronik } \\
\text { buatan Indonesia } \\
\text { handal }\end{array}$ & 2 & 8 & 21 & 37 & 15 & 11 & 6 & 412 & 4,12 & $\begin{array}{l}\text { Cukup } \\
\text { percaya }\end{array}$ \\
\hline \multicolumn{8}{|c|}{ Rata-Rata Total X2 } & 426 & 4,26 & $\begin{array}{l}\text { Cukup } \\
\text { percaya }\end{array}$ \\
\hline
\end{tabular}

Tabel 3. Lanjut

\begin{tabular}{|c|c|c|c|c|c|c|c|c|c|c|}
\hline \multirow{2}{*}{$\begin{array}{l}\text { Item willingness } \\
\text { to buy }\end{array}$} & \multicolumn{7}{|c|}{ Frekuensi Skor Jawaban } & \multirow{2}{*}{ Total } & \multirow{2}{*}{$\begin{array}{l}\text { Rata- } \\
\text { rata }\end{array}$} & \multirow{2}{*}{ Kategori } \\
\hline & 1 & 2 & 3 & 4 & 5 & 6 & 7 & & & \\
\hline $\begin{array}{l}\text { Saya ingin } \\
\text { membeli produk } \\
\text { elektronik buatan } \\
\text { Indonesia }\end{array}$ & 2 & 6 & 19 & 29 & 21 & 13 & 10 & 440 & 4,40 & Ingin \\
\hline $\begin{array}{l}\text { Saya akan membeli } \\
\text { produk elektronik } \\
\text { buatan Indonesia } \\
\text { bila nanti saya } \\
\text { membutuhkan } \\
\text { produk elektronik }\end{array}$ & 2 & 9 & 9 & 33 & 22 & 13 & 12 & 451 & 4,51 & Ingin \\
\hline $\begin{array}{l}\text { Saya ingin } \\
\text { mencoba produk } \\
\text { elektronik buatan } \\
\text { Indonesia }\end{array}$ & 2 & 5 & 12 & 27 & 17 & 24 & 13 & 476 & 4,76 & Ingin \\
\hline \multicolumn{8}{|c|}{ Rata-Rata Total } & 456 & 4,56 & Ingin \\
\hline
\end{tabular}

\section{Hasil Uji Hipotesa}

Dengan menggunakan software AMOS 21, diketahui hasil uji pengaruh langsung sebagamana terlihat pada tabel 4 berikut ini. . 
Tabel 4Hasil Uji Hipotesa

\begin{tabular}{|c|c|c|c|}
\hline Hipotesa/jalur & Estimate & Signifikansi & Kesimpulan \\
\hline $\begin{array}{l}\text { H1: Consumer Ethnocentrism } \\
\rightarrow \text { Domestic Product Belief }\end{array}$ & 0,524 & $* * *$ & Terdukung \\
\hline $\begin{array}{l}\text { H2: Consumer Ethnocentrism } \\
\rightarrow \text { Willingness to Buy }\end{array}$ & 0,267 & $* * *$ & Terdukung \\
\hline $\begin{array}{c}\text { H3: Domestic Product Belief } \\
\rightarrow \text { Willingness to Buy }\end{array}$ & 0,690 & $* * *$ & Terdukung \\
\hline
\end{tabular}

Keterangan :*** signifikan pada $p<0.000$

Tabel 4 menunjukkan bahwa Hipotesa 1 hingga 3 terdukung oleh data yang berarti pengaruh lansung antar variabel sebagaimana dirumuskan dalam masing-masing hipotesa dapat diterima. Sementara itu,Consumer Ethnocentrism memiliki pengaruh positif terhadap Willingness to buy melalui domestic Product Belief sebesar 0,362 $(0,524 * 0,690)$ pada taraf signifikansi $0,000(0,000 * 0,000)$. Dengan demikian persamaan analisis pathnya adalah: Willingness to buy $(\mathrm{Y})=0,362 \mathrm{X}+\dot{\varepsilon}$. Dengan demikian dapat dikatakan bahwa seluruh hipotesa terdukung oleh data.

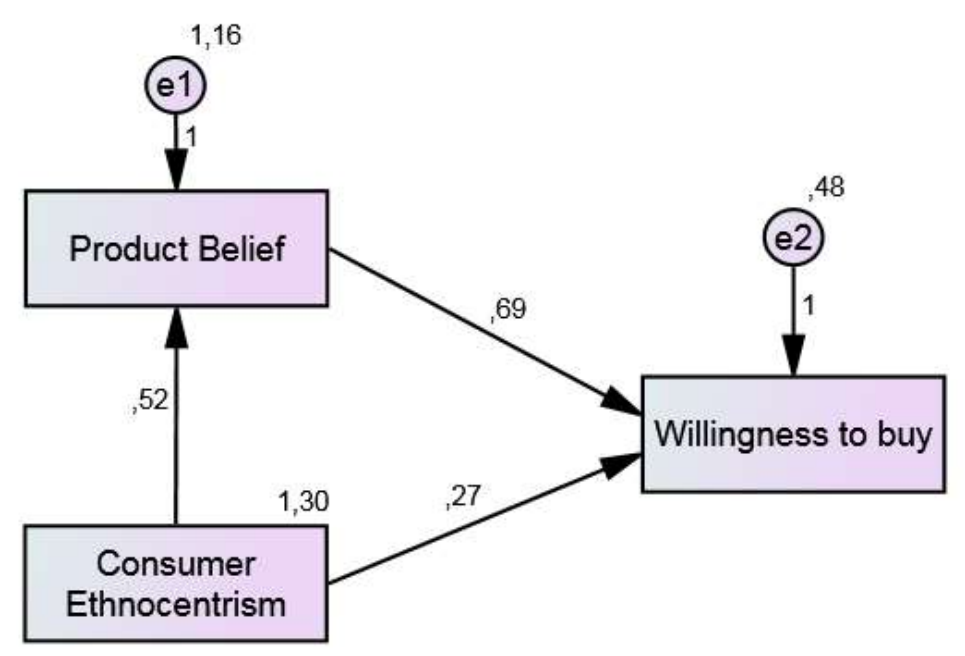

Sumber : Lampiran 5

Keterangan :

Jalur Consumer Ethnocentrism $\rightarrow$ Domestic Product Belief signifikan

Jalur Consumer Ethnocentrism $\rightarrow$ Willingness To Buy signifikan

Jalur Domestic Product Belief $\rightarrow$ Willingness To Buy signifikan

Adapun persamaan regresinya sebagai berikut:

Domestic Product Belief $(\mathrm{Z})=0,524 \mathrm{X}+\dot{\varepsilon}$

Willingness to buy $(\mathrm{X})=0,267 \mathrm{X} 1+\dot{\varepsilon}$

Willingness to buy $(\mathrm{Y})=0,690 \mathrm{Z}+\dot{\varepsilon}$

Pada Tabel 4dapat dilihat bahwa besarnya pengaruh dari Consumer Ethnocentrism terhadap Domestic Product Belief sebesar 0,524 pada taraf signifikansi 0,000 
$(p<0.0001)$. Taraf signifikansi untuk pengaruh antar variabel sebesar 0,000 di mana nilai ini lebih kecil dari standar toleransi kesalahan sebesar 5\% $(0,05)$ yang berarti signifikan. Sehingga dapat disimpulkan bahwa semakin kuat consumer ethnocentrism semakin kuat pula domestic product belief, dengan demikian hipotesa pertama yang diajukan dapat diterima atau terdukung.Hasil penelitian ini mengindikasikan bahwa konsumen dengan kecenderungan ethnocentrisme yang kuat akan cenderung mengevaluasi produk dalam negeri menggunakan pertimbangan emosional karena rasa cinta yang kuat terhadap negaranya. Sebaliknya bila kecenderungan ini lemah, maka konsumen akan mengevaluasi produk elektronik dalam negeri secara rasional dan bahkan akan menilainya dengan membandingkannya dengan keunggulan produk dari negara lain. (Balabani et al., 2001; Watson \& Wright, 2000; Abedniya \& Zaem, 2011). Penelitian ini juga menunjukkan bahwa kecenderungan ethnoceentrism pada kalangan mahasiswa yang merupakan generasi muda terdidik dan akan menjadi generasi penerus belum dapat dikatakan sangat kuat. Hal ini patut disayangkan karena seharusnya mereka memiliki kebanggaan dan keberpihakan terhadap dalam negeri sehingga produk dalam negeri mampu bersaing di pasar domestik. Kecenderungan ethnocentris di kalangan mahasiswa menggambarkan rasa bangga dan nasionalisme mereka dalam bentuk perilaku mereka sebagai konsumen, seberapa besar dukungan mereka terhadap produk, industri dan ekonomi dalam negeri.

Tabel 4 menunjukkan bahwa besarnya pengaruh dariDomestic Product Belief terhadap Willingness to buyadalah sebesar 0,690 pada taraf signifikansi 0,000 $(\mathrm{p}<0.000)$ atau lebih kecil dari standar toleransi kesalahan sebesar 5\% $(0,05)$ Hasil ini menunjukkan bahwa hipotesa ke dua terdukung atau dapat diterima. Hasil penelitian ini sejalan dengan penelitian yang pernah dilakukan untuk beberapa kategori produk (Sulhaini, 2016). Hasil penelitian ini menegaskan bahwa ketika konsumen memiliki hasil evaluasi yang baik dan keyakinan kuat terhadap produk elektronik dalam negeri akan mendorong konsumen untuk membeli produk elektronik dalam negeri. Ini tentunya menunjukkan bahwa konsumen yang rasional akan terdorong untuk membeli produk buatan dalam negeri ketika mereka memiliki keyakinan yang kuat terhadap produk elektronik dalam negeri.

Selanjutnya, Tabel 4. secara jelas menunjukkan bahwa besarnya pengaruh dari Consumer Ethnocentrism terhadap Willingness to buy sebesar 0,267 pada taraf signifikansi $0,000(\mathrm{p}<0.000)$ atau lebih kecil dari standar toleransi kesalahan sebesar 5\% $(0,05)$ yang berarti signifikan. Sehingga dapat disimpulkan bahwa terdapat pengaruh yang signifikan dan hipotesa tiga terdukung oleh data dan sehingga hipotesis ketigaditerima.Hasil penelitian ini sejalan dengan hasil penelitian sebelumnya (Powers et al., 2008; Rybina et al., 2010; Brkic et al., 2011). Namun perlu diingat bahwa tingkat kecenderungan ethnocentrism di kalangan mahasiswa belum kuat dan bila dibanding dengan jalur yang lain, regression weight dari jalur Consumer ethnocentrism willingness to buy yang terkecil. Ini menunjukkan pula bahwa kecenderungan ethnocentrism harus ditingkatkan lagi agar dapat memperkuat keinginan untuk membeli produk buatan dalam negeri. Konsumen yang memiliki kecenderungan ethnocentrism yang kuat akan memiliki dorongan moral yang kuat untuk membeli produk elektronik buatan dalam negeri dan sebaliknya membeli produk impor justru dianggap sebagai bentuk ketidak setiaan terhadap bangsa sendiri. 


\section{KESIMPULAN DAN SARAN}

Penelitian ini bertujuan untuk menguji pengaruh consumer ethnocentrism terhadap domestic product belief dan willingness to buy di kalangan mahasiswa di Mataram. Adapun sampel diambil di Universitas Mataram yang memiliki mahasiswa yang sangat heterogen. Terdapat beberapa kesimpulan penting yang dapat ditarik dari hasil studi ini.

Pertama, Kecenderungan ethnocentrisme di kalangan mahasiswa belum bisa dikatakan sangat kuat (lebih tepat disebut medium). Hal ini terlihat pula pada tingkat kepercayaan dan keiginan untuk membeli produk elektronik dalam negeri. Namun demikian, dari penelitian ini diketahui bahwa semakin kuat consumer ethnocentrism semakin kuat pula domestic product belief. Konsumen dengan kecenderungan ethnocentrism yang kuat akan memiliki keyakinan kuat terhadap produk elektronik dalam negeri. Keyakinan ini dapat dipengaruhi oleh sisi emosional dari kecenderungan ethnocentrism pada diri konsumen. Mereka akan menilai secara positif produk elektronik dalam negeri. Namun demikian, sebagaimana terlihat pada pembahasan setiap variabel tampak bahwa kecenderungan dan tingkat domestic product belief belum dapat dikatagorikan sangat kuat.

Kedua, semakin kuat domestic product belief semakin kuat willingenness to buy produk dalam negeri. Keinginan untuk membeli produk elektronik buatan dalam negeri akan menguat bilamana konsumen memiliki keyakinan yang kuat terhadap produk dalam negeri. Kedua variabel ini menunjukkan tingkatan "sedang" yang berarti belum dapat dikatakan sangat kuat.

Ketiga, semakin kuat consumer ethnocentrism semakin kuat willingness to buy produk buatan dalam negeri. Kecenderungan ini memiliki pengaruh yang paling kecil dibanding jalur yang lain. Terakhir, consumer ethnocentism secara tidak langsung berpengaruh terhadap willingness to buy melalui product belief produk dalam negeri

\section{DAFTAR PUSTAKA}

Abedniya, A., and Zaem, M.N. (2011) 'The impact of country of origin and ethnocentrism as major dimensioins in consumer purchasing behaviour in fashion industry', European Journal of Economics, Finannce and Administrative Sciences, Vol. 33, pp. 222-232.

Al Ganideh, S.F., and Al Taee, H. (2012) 'Examining consumer ethnocentrism amongst Jordanians from an ethnic group perspective',International Journal of Marketis Studies, Vol. 4, No. 1, pp. 48-57.

Auruskeviciene, V., Vianelli, D., Reardon, J. 2012. Comparison of Consumers Ethnocentrism behavioural patterns in Transitional Economies, Transformation in Business and Economics, vol. 11. No. 2, pp. 20-35.

Balabanis, G., Diamantopoulos, A., Mueller, R.D and Melewar, T.C. (2001) 'The impact of nationalism, patriotism and internationalism on consumer ethnocentric tendency', Journal of International Business Studies, Vol. 32., No. 1, pp. 157 175.

Baker, M.J., and Ballington, L. (2002) 'Country of origin as a source of competitive advanrage' Journal of Strategic Marketing, Vol. 10, pp. 157 - 168.

Bawa, A. (2004) 'Consumer ethnocentrism: CETSCALE validation and measurement 
of extent'.Vikalpa, Vol. 29, No. 3, pp. 43-57.

Banfo, B.A. (2012) 'Consumer attitude toward products made in Ghana', Global Journal of Business Research, Vol. 6, No. 1, pp. 39-46.

Barbu, C., M. (2011) 'The meanings of made in Romania among the Romanian consumers', Theoretical and Applied Economics, Vol. XVIII, No. 7, pp. 31-42.

Biswas, K., Chowdhury, MKH., and Kabir, H. (2011) 'Effects of price and country of origin on consumer product quality perceptions: An empirical study in Bangladesh', International Journal Of Management, Vol. 28, No. 3, pp. 659674.

Brkic, N., Corbo, M. and Berberovic, D. (2011) ' Ethnocentrim and animosity in consumer behavior in Bosnia and Herzegovina and Implications for Companies',Economic Review - Journal of Economics and Business, Vol. IX, No. 1, pp. 45-61.

Chinen, K., and Sun, Y. (2011) 'Effects of country of origin on buying behaviour', International Journal of Management, Vol. 28, No. 2, pp. 553-563.

Dinnie, K. (2004) 'Country of origin 1965 -2004: A literature review', Journal of Customer Behaviour, Vol 3, No. 2, pp. 165-213.

Hair, J.F., Black, W.C, Babin, B.J., Anderson, R.E., and Tatham, R.L. 2006 Multivariate Data Anlysis. Pearson Education International. New Jersey.

Huddleston, P., Good, L.K., and Stoel. L. 2001. Consumer ethnocentrism, product necessity and Polish consumers' perceptions of quality, International Journal of Retail and Distribution Management, vol. 29. No.5, pp. 236-246.

Jain, S. K. And Jain, R. 2013. Consumer Ethnocentrism and Its Antecedents: An Exploratory Study of Consumers in India, Asian Journal of Business Research, vol 3, no 1, pp. 1-18.

Karami, M., Pourian, S. and Olfati, O. (2011). Iranian Consumers and Products Made in China: A Case Study of Conumers Behaviour in Iran's Market. International Journal of China Marketing, 2 (1), pp. 58-67.

Lantz, G., and Loeb, S. (1996) 'Country of origin and ethnocentrism: An nalysis of Canadian and American preferences using social identity theory',Advances in Consumer Research, Vol. 23, pp. 374-378.

Mohamed,A.S.P., Sulaiman, S.H.H., Othman, M.F., Yang, M.A.C, J., Haron, H., 2011. Patritism Dilema Among Young Malaysian Youth between Strategy and Reality, International Journal of Business and Social Sciences., vol 12. No 16., pp. 219-227.

Notari, M., Ferencz, A, Levai, P. and Czegledi, M. (2011) 'Marketing analysis of the connection of food sovereignity and consumers' patriotism in Hungary',International Journal of Management Cases, Vol.13, no. 3, pp. 607615.

Oberecker, E.M. And Diamanopoulos, A. (2011) 'Consumers' emotional bonds withforeign countries: Does consumer affinity affect behavioural intentions?',Journal of International Marketing, Vol. 19, No. 2, pp. 45-72.

Orth, U.R., and Firbasova, Z., (2003)'The role of consumer ethnocentrism in food product evaluation',Agribusiness, Vol. 19, No. 2, pp. 137-153.

Oyeniyi, O. (2009) 'Analysis of Nigerian consumers' perception of foreign products',Buletinul, Vol.1, No. XI, pp. pp. 18-26.

Phau, I. (2010)'An Australian perspective of the effects of brand image and product quality on diffusion brands of designer jeans',Journal of Global Business and 
Technology, Vol.6, No. 1 (Spring), pp. 41-51.

Powers, N., Fetscherin, M., Coolege, R., and Park, W. (2008) 'Measuring the joint effect of country image and brand perception in conumer evaluations of televisions: The case of China and Malaysia',The Business ReviewCambrigde, Vol. 9, No. 2, pp. 145-152.

Rybina, L., Reardon, J. and Humprey, J. (2010) 'Patriotism, cosmopilitanism, consumer ethnocentrism and purchase behaviour in Kazakhstan', Organisations and Market in Emerging Economies, Vol.1. No. 2, pp. 92-107.

Shah, K.A.M. and Ibrahim, H.I. 2012., Consumer Ethnocentrism: Does it really matter for Malaysian Consumers? West East Journal of Social Sciences, Vol. 1 No. 1, pp. 26-37.

Shankarmahesh, 2006. Consumer Ethnocenrtism: An Integrative Review of its Antecedents and consequences, International Marketing Review, vol. 23. No. 2, pp.146-172.

Sharma, P. 2015. Consumer ethnocentrism: Reconceptualization and Cross-cultural validation, Journal of Business Studies, 46. pp. 381-389.

Shimp. T. And Sharma, S., (1987)'Consumer ethnocentrism: construction and validation of the CETSCALE',Journal of Marketing Research, Vol. XXIV, pp. 280-289.

Shirin, K., and Kambiz, H.. (2011) 'The effect of the country of origin image, product knowledge and product involvement on consumer purchase decisions' Chinese Business Review, Vol. 10. No. 8, pp. 601-615.

Speece, M. and Nguyen, D.P. (2005) 'Countering negative effect of country of origin with low pricess: a conjoint study in Vietnam',Journal of Product and Brand Management, Vol. 14, No. 1, pp. 39-48.

Sulhaini. 2016. Home country image and ethnocentrism among young consumers in a developing country. Journal for Global Business Advancement 9 (2):195 - 211.

Sulhaini, and L. E. H. Mulyono. 2015. The Effect of Ethnocentrism and Image of Asian Industrialised Countries on Perceived

Wang, X., and Yang, Z. (2008) 'Does country of origin matter in the relationship between brand personality and purchase intention in emerging economies?', International Marketing Review, Vol. 25, No. 4, pp. 458-474.

Watson, J.J. and Wright, K. (2000) 'Consumer ethnocentrism and attitudes Toward domestic and foreign products', European Journal of Marketing, Vol. 34, No. 9/10, pp. 1149-1166.

Widarjono, A., 2010, Analisis Statistika Multi Variat Terapan, UPP STIM YKPN, Yogyakarta

Yim , W.C., Garma, R., and Polonsky, M.J. (2007) 'Product evaluation and purchase intention: impact of country-of-origin and experience in living in aforeign country', Sunway Academic Journal, Vol. 4, pp. 13-26. 